\title{
Effects of Five Growing Media and Two Fertilizer Levels on Polybag-Raised Camden Whitegum (Eucalyptus benthamii Maiden \& Cambage) Seedling Morphology and Drought Hardiness
}

\author{
Mohammad Nasir Shalizi ${ }^{1}$ (D), Barry Goldfarb ${ }^{1, *}$, Owen Thomas Burney ${ }^{2}$ and \\ Theodore Henry Shear ${ }^{1}$ \\ 1 Department of Forestry and Environmental Resources, North Carolina State University, Raleigh, \\ NC 27695-8008, USA \\ 2 John T Harrington Forestry Research Center, Department of Plant and Environmental Sciences, New Mexico \\ State University, 3021 Highway 518, Mora, NM 87732, USA \\ * Correspondence: bgg@ncsu.edu; Tel.: +1-919-515-4471
}

Received: 22 April 2019; Accepted: 26 June 2019; Published: 28 June 2019

check for updates

\begin{abstract}
In developing countries, tree seedlings are often produced in polybags filled with mixtures of locally available materials. Seedling growth and quality can be affected by the type and amount of these substrates used in the mixture. Differences in seedling growth and quality can also be significantly affected when fertilization is employed during the nursery growing period. In this study, we assessed the effects of five different growing media and two fertilization regimes on nursery growth, seedling morphology and early post-planting response to drought of Eucalyptus benthamii (Maiden \& Cambage) seedlings. First, we evaluated the effects of each media by fertilizer treatment combination on morphological attributes during a nursery growing period. Seedlings raised in fertilized media without rice hulls yielded higher growth, root dry mass, shoot dry mass, total dry mass, Dickson quality index (DQI) scores, and number of first order lateral roots (FOLRs). Root to shoot ratio (R:S ratio) was, however, greater in non-fertilized media that contained rice hulls. We then conducted a simulated outplanting and drought hardiness experiment, in which seedlings were planted in $13.2 \mathrm{~L}$ containers and irrigated for one month, followed by the imposition of drought stress. Seedlings in fertilized media composed of sand, topsoil and compost showed greater growth than those in rice hull-containing media, during the irrigation phase. With the discontinuation of irrigation and prevention of precipitation reaching the seedlings, seedlings grown in non-fertilized media containing rice hulls survived longer than those in other media. There were no large differences in survival among other media or between fertilized and other non-fertilized seedlings. Seedling total size and shoot height at the time of planting played a major role in survival. Smaller seedlings with smaller shoot sizes and greater R:S ratios survived longer. This study demonstrates that growing media and fertilization can be manipulated to affect seedling morphology in the nursery and, ultimately, seedling performance and survival under water stressed conditions.
\end{abstract}

Keywords: seedling growth; nutrition; seedling quality; survival; xylem water potential; reforestation

\section{Introduction}

In afforestation or reforestation programs, it is important to produce seedlings in nurseries that will survive and grow well after outplanting. The target seedling concept proposes that morphological and physiological characteristics of seedlings can be tailored for specific outplanting conditions [1]. Under droughty conditions, survival of tree seedlings is affected by inadequate soil water [2] and, in newly 
planted seedlings, water stress can be higher due to weak root contact with soil particles [3]. Once planted, a seedling needs to be morphologically and physiologically capable of coping with drought stress [4]. Morphology and physiology are two important factors that affect seedling quality [5], survival, and growth on site. Seedling morphological attributes in the nursery have been positively correlated with hardwood and pine species growth [6] and survival [7] in the field; although the significance of the correlations differed among species and was variable among morphological attributes.

Among morphological attributes, shoot height in the nursery is not a clear indicator of field survival. Thompson [8] found that height has an unpredictable effect on survival of planted seedlings on dry sites. Sharma et al. [9] observed a significant negative relationship between height at time of planting and field survival of Pinus radiata D. Don seedlings. Others indicate no correlations between nursery height and field survival [10,11].

Root to shoot ratio (R:S) is another morphological attribute that can affect survival after planting [12]. Seedlings with larger shoot sizes can grow better due to greater photosynthetic capacity if there is adequate moisture, but they also can have higher transpiration and reduced survival on dry sites [13]. For optimal survival and growth, it is important to produce seedlings with balanced root systems and shoots [13]. Seedlings with larger root systems, higher root system fibrosity, and smaller shoots (greater R:S ratio) might be preferable for arid conditions. Sands [14] suggested that larger root systems increase the likelihood of seedling survival due to their higher water absorption surface area, and can increase the ability of newly planted seedlings to survive drought [15].

Seedling morphological traits can be affected by nursery cultural practices [15]. The components of growing media used in container nurseries are important in the growth and development of seedlings. Peat moss, perlite, and vermiculite are commonly used in many developed countries. In less-developed countries, these commercial substrates are typically too expensive to use. However, locally available materials such as rice hulls, compost, sawdust, and wheat straw can be incorporated with soil and sand to formulate growing media [16]. Soil is usually obtained from nursery beds and sand from river beds. Sand increases porosity [17] of the media, and compost affects chemical and physical properties, enhancing water holding capacity, increasing porosity, and providing nutrients [17]. Compost (composted manure) is the only readily available organic material that is commonly used as part of growing media in developing countries.

The combination of soil, sand, and compost can provide good growing media for containerized seedlings. Shrivastava et al. [18] studied the effects of different substrate mixtures on growth of seedlings of a Eucalyptus hybrid raised in containers. Seedlings grown in a mixture of soil, sand, and compost (2:1:2) had larger heights, root collar diameters (RCDs), and root biomass than seedlings in a mixture of compost, coarse sand, and coal pebbles. Although standards for growing media have not yet been determined for forest tree species in some developing countries, media used for polybags in nurseries is often a 1:2:1 mixture of sand, compost and topsoil [16] or 3:1:2 mixture of topsoil, compost and sand [19]. Rice hulls could be a medium component with good potential in regions that grow rice. Due to its physical characteristics, non-composted rice hulls can improve porosity and drainage in growing media [20,21] and can potentially substitute for vermiculite and perlite [22]. Studies on Pinus halepensis Miller., Eucalyptus grandis W. Hill ex Maiden, Eucalyptus dunnii Maiden., and Juniperus chinensis pfitzerianna L. have shown that 20 to $50 \%$ parboiled, carbonized, and or composted rice hulls incorporated into growing media can have positive effects on seedling morphological attributes [23-26].

Seedling mineral nutrition is also an important factor in seedling production systems [27]. Fertilization is a usual practice in many nursery operations; however, it is not very common in nurseries in some developing countries [16]. Fertilization enhances seedling growth and development during the nursery growing period and quality of seedlings can be improved by managing the type, amount, and timing of fertilization [28]. Nitrogen $(\mathrm{N})$, phosphorus $(\mathrm{P})$, and potassium $(\mathrm{K})$ are three important macroelements that are crucial in the early stage of seedling development. Adequate availability of $\mathrm{N}$ in leaves is necessary for photosynthesis that ultimately enhances shoot and root development [29]. 
Studies in Eucalyptus camaldulensis Dehnh., E. benthamii, and E. dunnii reported enhanced shoot and root development with $\mathrm{N}$ and $\mathrm{P}$ fertilization in the nursery [30,31].

Previous research on the effects of nursery fertilization on survival of planted seedlings has yielded contradictory results. Oliet et al. [29] suggested that fertilization influenced nutrient reserves and morphology of $P$. halepensis seedlings and enhanced resistance to drier conditions. In their study, Chamshama and Hall [30] found higher survival rates of E. camaldulensis seedlings with increasing K fertilization. High outplanting survival was found for Pinus canariensis C.Sm., Quercus coccifera L., Quercus ilex L., and P. halepensis seedlings fertilized in the nursery [29,32-34]. However, Trubat et al. [35] found that nursery fertilization affected growth and morphology of Quercus suber L. in the nursery, but did not affect field performance after planting and Pharis and Kramer [36] observed reduced field survival of loblolly pine (Pinus taeda L.) seedlings fertilized with high levels of $\mathrm{N}$ during nursery growth. A higher supply of $\mathrm{N}$ in the nursery can enhance shoot growth, but can increase water stress due to greater transpiration if planted on dry sites [28].

Eucalyptus species are commonly planted in many tropical and sub-tropical regions of the world [37-39] because of their rapid growth and desirable wood properties [40]. Eucalyptus benthamii is one species that is widely planted in Brazil for pulp wood, paper, and fuelwood [40,41]. Most E. benthamii seedlings are grown in nurseries using plastic containers or polybags with a range of media mixtures depending on the growing location and available resources [38]. One major challenge for outplanted seedlings is surviving droughty conditions. As climate patterns begin to shift, some outplanting environments will be exposed to harsher and drier conditions that will likely impact the growth and physiology of newly planted seedlings [42,43]. In this study, we used simulated drought to mimic such outplanting conditions and relate nursery morphological attributes to post-planting survival and relative drought tolerance.

The objectives of this research were to: (i) determine the effects of growing media mixtures composed of various proportions of topsoil, sand, compost, and rice hulls and two fertilization regimes on growth and morphological attributes of E. benthamii seedlings raised in polyethylene bags; (ii) particularly, to test the effects of rice hulls substituted for compost and top soil currently used in developing countries; and (iii) to evaluate the effects of seedling morphology on drought hardiness and survival under induced drought stress in a simulated outplanting environment.

\section{Materials and Methods}

\subsection{Nursery Phase}

\subsubsection{Plant Material}

Seeds from a bulk lot of open-pollinated trees in a seed orchard in Brazil were sown on 5 October 2013 in a mixture of peat moss and vermiculite in $0.036 \mathrm{~m}^{3}$ starter trays in a greenhouse on the North Carolina State University campus (Raleigh, NC, USA). The greenhouse temperature was maintained at an average of 22 degrees Celsius (ranged between 18 to 30 degrees). The relative humidity ranged between 45 to 91 percent with an average of 70 percent. The light ranged from less than 100 to approximately $550 \mu \mathrm{mol} \cdot \mathrm{m}^{-2} \cdot \mathrm{s}^{-1}$. Seedlings were transplanted into $750 \mathrm{~mL}$ perforated polybags $(7 \mathrm{~cm}$ in diameter and $20 \mathrm{~cm}$ in height, with 24 holes each with a diameter of $0.5 \mathrm{~cm}, 16$ on the sides and 8 on the bottom) in mid-November 2013. Seedlings were treated with fungicide three times for damping-off and powdery mildew. Fungicide was first applied a week after germination and two times after transplanting into the polybags in November and December 2013. On 26 January 2014, a greenhouse mechanical failure resulted in freezing damage and mortality of many of the seedlings. On 11 February 2014 all surviving seedlings were pruned to a height of $7 \mathrm{~cm}$ in order to stimulate re-sprouting and establish a uniform height to evaluate growth after the frost event. Seedlings were moved outside on 1 April 2014 and placed on benches receiving full sunlight. 


\subsubsection{Treatments}

Treatments consisted of growing substrates and fertilization regimes. There were five different growing substrates composed of different combinations of sandy loam soil (obtained from a nursery bed at Horticulture Field Laboratory, North Carolina State University, Raleigh, NC, USA), Paveston ${ }^{\circledR}$ Natural Play sand (Bonsal American/an Oldcastle Company, Charlotte, NC, USA), Black Kow ${ }^{\circledR}$ compost (Black Gold Compost Company, Oxford, FL, USA), and parboiled rice hulls (Natures Media Amendments, Riceland Foods, Stuttgart, AZ, USA). Two fertilizer regimes, fertilization, and control (no fertilization) were applied to each medium mixture creating ten substrate $\times$ fertilization treatment combinations (Table 1). The fertilizer was water soluble granular NPK 10:10:10 Weaver Lawn and garden PLANT FOOD (Winston Weaver Co. Inc., Winston-Salem, NC, USA). This fertilizer also contained $3 \% \mathrm{Ca}$ and $6 \% \mathrm{~S}$. For simplicity purposes, substrate names are abbreviated (topsoil $=\mathrm{TS}$, sand $=S$, compost $=C$, rice hull $=R H$ ) and fertilization regimes (fertilized $=F$, non-fertilized $=N F$ ) for the different combinations. Media TS-C-S and S-C-TS are currently used in nurseries [16,19]. C-S-TS is used as an alternative growing media [44]. RH-S-TS and RH-C-S are two new growing media tested in this study. In RH-S-TS, rice hulls are used to substitute for the compost in C-S-TS and, in RH-C-S, rice hulls are used to substitute for the soil in TS-C-S. Soil, sand, and compost media mixtures had higher bulk and particle density and lower porosity than rice hull media (Table 2).

Table 1. Treatment combinations based on four substrate types and two fertilization regimes used to grow E. benthamii seedlings. $\mathrm{C}=$ compost, $\mathrm{S}=$ Sand, $\mathrm{TS}=$ topsoil, $\mathrm{RH}=$ rice hulls, $\mathrm{F}=$ fertilized $(2000$ $\mathrm{mg}), \mathrm{NF}=$ non-fertilized.

\begin{tabular}{|c|c|c|c|c|c|c|}
\hline \multirow{2}{*}{ Medium } & \multicolumn{4}{|c|}{ Substrates (\%) } & \multirow{2}{*}{ Fertilization } & \multirow{2}{*}{ Treatment } \\
\hline & Top Soil & Sand & Compost & Rice Hull & & \\
\hline C-S-TS & 17 & 33 & 50 & - & $\begin{array}{c}\mathrm{F} \\
\mathrm{NF}\end{array}$ & $\begin{array}{c}\text { C-S-TS(F) } \\
\text { C-S-TS(NF) }\end{array}$ \\
\hline TS-C-S & 50 & 17 & 33 & - & $\begin{array}{c}\mathrm{F} \\
\mathrm{NF}\end{array}$ & $\begin{array}{c}\text { TS-C-S(F) } \\
\text { TS-C-S(NF) }\end{array}$ \\
\hline S-C-TS & 25 & 50 & 25 & - & $\begin{array}{c}\mathrm{F} \\
\mathrm{NF}\end{array}$ & $\begin{array}{c}\text { S-C-TS(F) } \\
\text { S-C-TS(NF) }\end{array}$ \\
\hline RH-S-TS & 17 & 33 & - & 50 & $\begin{array}{c}\mathrm{F} \\
\mathrm{NF}\end{array}$ & $\begin{array}{l}\text { RH-S-TS(F) } \\
\text { RH-S-TS(NF) }\end{array}$ \\
\hline RH-C-S & - & 17 & 33 & 50 & $\begin{array}{c}\mathrm{F} \\
\mathrm{NF}\end{array}$ & $\begin{array}{c}\text { RH-C-S(F) } \\
\text { RH-C-S(NF) }\end{array}$ \\
\hline
\end{tabular}

Table 2. Bag weight, bulk density (B.D), particle density (P.D), porosity, gravimetric moisture content (M.C), and amount of water drained out of $500 \mathrm{~mL}$ within five minutes from each media type.

\begin{tabular}{ccccccc}
\hline Medium & $\begin{array}{c}\text { Bag Weight } \\
(\mathbf{g})\end{array}$ & B.D $\left(\mathbf{g} / \mathbf{c m}^{\mathbf{3}}\right)$ & P.D $\left(\mathbf{g} / \mathbf{c m}^{3}\right)$ & Porosity (\%) & M.C (\%) & $\begin{array}{c}\text { Drainage } \\
(\mathbf{m L})\end{array}$ \\
\hline C-S-TS & 972 & 1.1 & 1.4 & 23.4 & 41.0 & 355.0 \\
TS-C-S & 1016 & 1.3 & 1.5 & 10.4 & 32.4 & 118.8 \\
S-C-TS & 1222 & 1.3 & 1.6 & 16.9 & 28.7 & 245.0 \\
RH-S-TS & 794 & 0.8 & 1.3 & 33.8 & 30.5 & 365.0 \\
RH-C-S & 670 & 0.5 & 0.7 & 32.5 & 73.8 & 377.5 \\
\hline
\end{tabular}

${ }^{\dagger}$ C-S-TS $=$ compost $(50 \%)+$ sand $(33 \%)+$ topsoil $(17 \%)$, RH-S-TS $=$ rice hull $(50 \%)+$ sand $(33 \%)+$ topsoil $(17 \%)$, TS-C-S = topsoil $(50 \%)+$ compost $(33 \%)+$ sand $(17 \%)$, S-C-TS $=$ sand $(50 \%)+\operatorname{compost}(25 \%)+$ top soil $(25 \%)$ and RH-C-S $=$ rice hull $(50 \%)+$ compost $(33 \%)+$ sand $(17 \%)$.

\subsubsection{Fertilization and Irrigation}

Fertilization treatments were applied four times during the growing season: a top dressing of $400 \mathrm{mg}$ in January and March 2014 and $600 \mathrm{mg}$ in April 2014 and May 2014 (total of 2000 mg). Irrigation 
varied according to the growing stage. During the first five weeks, seedlings were irrigated to field capacity every other day. After five weeks, irrigation occurred when containers dried down to $90 \%$ of water holding capacity. In order to accurately define soil moisture and irrigation applications, an Irrometer ${ }^{\circledR}$ (Riverside, CA, USA) tensiometer-Model MLT was used to measure soil water potential of two seedlings per media treatment. On average, it took 6 days after watering for each sample to fall to $90 \%(-37 \mathrm{kPa})$ of its field capacity. In order to have uniform irrigation, at each time of irrigation, every seedling was watered for $5 \mathrm{~s}$.

\subsubsection{Experimental Design}

The study was established as a randomized complete-block design with a $2 \times 5$ factorial arrangement of treatments replicated with 18 blocks. Six seedlings from each treatment were randomly placed in each block (60 seedlings per block surrounded by border seedlings). At the beginning of the study, there were 108 seedlings in each treatment. The initial seedling count totaled 1080. However, due to mortality, the final seedling size decreased to 889 . The surviving number of seedlings ranged from 105 in the RH-C-S(NF) treatment to 61 in the TS-C-S(F) treatment. Seedling size per treatment per block was six for most treatments in most blocks, however, it ranged from 2 in TS-C-S(F) to 6 in most of other treatments.

\subsubsection{Measurements}

In May 2014, nursery shoot height $(\mathrm{cm})$ and root collar diameter $(\mathrm{RCD}, \mathrm{mm})$ were measured on all surviving seedlings (889). After these measurements, on average, three seedlings per block per each treatment were randomly selected for destructive sampling (total of 533; treatments ranged from 30 to 68 seedlings). Shoots were separated from roots and the number of spiraled roots and number of first order lateral roots (FOLRs) were measured on a sub-sample of 204 seedlings from seven blocks (seedling numbers ranged from 13 to 25 per treatment). In addition, the number of active root tips was measured on a sub-sample of 57 seedlings (three to six seedlings per treatment). Spiraled roots were counted for every destroyed seedling. We considered a lateral root as spiraled when it touched the edge or bottom of the polybag and grew horizontally $\frac{1}{4}$ of the circumference around the edge. FOLRs were counted for lateral roots $\geq 1 \mathrm{~mm}$ in diameter. The number of active roots tips were counted for lateral roots $\geq 1 \mathrm{~mm}$ in diameter. Active root tips are non-suberized, white root tips produced on lateral roots.

Next, the shoots and roots were oven dried at $60^{\circ} \mathrm{C}$ [7] for $72 \mathrm{~h}$ and weighed to the nearest hundredth of a gram. R:S ratio was calculated by dividing total root dry mass by shoot dry mass. Sturdiness [8] was calculated by dividing shoot height $(\mathrm{cm})$ by RCD $(\mathrm{mm})$. The Dickson quality index (DQI) [45] was calculated as:

$$
\mathrm{DQI}=\frac{\text { Total seedling dry weight }(\mathrm{g})}{\frac{\text { Height }(\mathrm{cm})}{\mathrm{RCD}(\mathrm{mm})}+\frac{\text { Shoot dry weight }(\mathrm{g})}{\text { Root dry weight }(\mathrm{g})}}
$$

For each treatment, the foliage of six randomly selected seedlings was combined, oven-dried and ground. Samples were analyzed by Waters Agricultural Laboratories, INC. (Camilla, GA, USA) for concentration $(\%)$ of nitrogen $(\mathrm{N})$, phosphorus $(\mathrm{P})$, potassium $(\mathrm{K})$, calcium $(\mathrm{Ca})$, magnesium $(\mathrm{Mg})$, sulfur $(\mathrm{S})$, iron $(\mathrm{Fe})$, boron $(\mathrm{B})$, zinc $(\mathrm{Zn})$, manganese $(\mathrm{Mn})$, and copper $(\mathrm{Cu})$ using the Inductively-Coupled Plasma (ICP) method [46]. The following equation was used to convert concentrations to contents for each nutrient and treatment combination:

$$
\text { Nutrient Content }=\frac{\text { Concentration }(\%) \times \text { Total Seedling Biomass }(\mathrm{mg})}{100}
$$

Two samples per medium mixture (Table 1), plus two samples each of rice hulls, sand, and soil were sent to Waters Agricultural Laboratories, INC. for chemical and physical analysis. These samples 
were analyzed for available ammonium $\left(\mathrm{NH}_{4}\right)$, nitrate $\left(\mathrm{NO}_{3}\right), \mathrm{P}, \mathrm{K}, \mathrm{Mg}, \mathrm{Ca}, \mathrm{S}, \mathrm{B}, \mathrm{Zn}, \mathrm{Mn}, \mathrm{Fe}$, and $\mathrm{Cu}$ as well as $\mathrm{pH}$, soluble salts, and organic matter using the Mehlich III procedure [47].

\subsection{Drought Test Phase}

\subsubsection{Experimental Design}

The drought hardiness test was conducted outdoors at North Carolina State University, $\left(35^{\circ} 47^{\prime} 29^{\prime \prime}\right.$ $\mathrm{N}, 78^{\circ} 41^{\prime} 53^{\prime \prime} \mathrm{W}$ ) with $355 \mathrm{E}$. benthamii seedlings from the nursery experiment. Seedlings from each of the medium $\times$ fertilizer treatment combinations were randomly assigned to another randomized complete block design with 12 blocks. We did not use the nursery experiment blocking structure for the drought hardiness test due to two reasons. First, we did not have seedlings from some treatments in all the blocks after destructive sampling. Second, we had to transplant seedlings in larger containers and had to move to a larger space. The block effect was insignificant for most response variables, allowing a new blocking structure to meet the new space requirements for the transplants. A combination of three seedlings per treatment were assigned in each block except that the TS-C-S(F) treatment only had two seedlings in some blocks (a total of 31 seedlings). Each block was surrounded by 26 border seedlings, also from the nursery experiment. Seedlings were transplanted into $13.2 \mathrm{~L}$ containers $(25 \mathrm{~cm}$ in diameter and $28 \mathrm{~cm}$ in height) filled with sandy loam soil and irrigated for 30 days. After a 30-day period, irrigation was discontinued and a 6-mm thick polyethylene greenhouse white plastic cover with $55 \%$ shade was placed $4 \mathrm{~m}$ above the seedlings to prevent rainfall and to expose the seedlings to drought stress until complete mortality (10 weeks). The western side of the cover was left open to allow air movement.

\subsubsection{Measurements}

After the 30-day irrigation period, height and RCD were measured. Using the nursery final height and RCD (initial) and 30-day height and RCD (final), absolute and relative growth was calculated using the following equations:

$$
\begin{gathered}
\text { Absolute Growth }(\mathrm{AG})=\text { Final }- \text { Initial } \\
\text { Relative Growth }(\mathrm{RG})=\frac{\text { Final }- \text { Initial }}{\text { Initial }} \times 100
\end{gathered}
$$

Once the drought stress treatment began, the trees were visually assessed every $48 \mathrm{~h}$ for permanent wilting and desiccation and the number of days until death (SurvDays) was recorded. Six seedlings per treatment were designated for shoot, pre-dawn water potential measurement (total of 60 seedlings). Pre-dawn shoot xylem water potential (XWP) was measured with a pressure chamber [48] at 2:00 a.m. Water potential was measured three times: on the first day of drought stress, on the 16th day of drought stress and on the 25th day of drought stress. At each sampling time, two seedlings per treatment combination were randomly selected for water potential measurement. Because E. benthamii leaves do not have petioles of sufficient size to be measured using the pressure chamber, stems ( $3-5 \mathrm{~cm}$ in length) from the top of the seedling were collected for water potential measurement. In some treatments, seedlings were very small and had only the main stem available for measurement, whereas in other treatments, lateral shoots were measured.

\subsection{Statistical Analysis}

Analyses of variance were performed on treatment means of each block. The sample size was 180 (18 blocks) for most of the nursery variables and 120 (12 blocks) for simulated drought test variables. Two-way ANOVA and type III sum of squares were used to test main effects of media, fertilizer, and their interaction at $\alpha=0.05$. Linear mixed models were used to fit the data in the GLIMMIX procedure in SAS 9.4@ 2014 (SAS Institute Inc., Cary, NC, USA). The Tukey-Kramer grouping was used 
to compare least square means of media type $\times$ fertilizer interactions (simple effects) at $\alpha=0.05$. The effect of fertilizer treatment was tested in each medium as well. All response variables were assessed for normality, independence, and constant variance assumptions. Residuals of response variables were independent, constant, and normally distributed. Due to the presence of zeros, the spiraled roots response variable was transformed using the equation $\sqrt{\mathrm{Y}}+\sqrt{\mathrm{Y}+1}$ prior to analysis in linear mixed model. The following linear mixed models were used to test effect of media type, fertilizer level, and their interaction on response variables:

$$
y_{i j k l}=\mu+M_{i}+F_{j}+M F_{i j}+B_{k}+\varepsilon_{i j k l}
$$

where $y_{i j k l}$ is the $l^{\text {th }}$ observation in $k^{\text {th }}$ block, $j^{\text {th }}$ fertilizer and $i^{\text {th }}$ media, $\mu$ is the overall mean, $M_{i}$ is fixed effect of media type $(i=1, \ldots, 5), F_{j}$ is fixed effect of fertilizer $(j=1,2), M F_{i j}$ is interaction of media type and fertilizer, $B_{k}$ is random block effect with expectations $B \sim \operatorname{NID}\left(0, \sigma_{b}^{2}\right)$, and $\varepsilon_{i j k l}$ is random error term with the expectations $\varepsilon_{i j k l} \sim \operatorname{NID}\left(0, \sigma_{\varepsilon}^{2}\right)$. Non-linear quadratic equations were fit to assess the relationships between the means of the seedling morphological attributes shoot height, RCD, total dry weight, and R:S ratio with the simulated drought test response variable number of SurvDays. Simple linear regression was used to describe the relationships between the dependent variable number of SurvDays and xylem water potential separately at each measurement time.

\section{Results}

\subsection{Nursery Morphological Attributes}

The interaction of media and fertilizer was significant for all nursery morphological response variables (Table 3). A general, yet brief, examination of the main effects suggests that the use of fertilizer resulted in larger seedlings compared to non-fertilized seedlings regardless of media type (Table 4). Additionally, media types containing some combination of compost, sand, and topsoil had greater heights, diameters, and biomass compared to media types using rice hulls regardless of the fertilization treatment. Exploring the results from the interaction in more detail revealed that with the addition of fertilizer, seedlings in the C-S-TS, TS-C-S, and S-C-TS medium types had the greatest mean heights. Those in the fertilized RH-C-S were significantly shorter than those in the TS-C-S and S-C-TS fertilized treatments. All the non-fertilized medium types produced seedlings with smaller heights than those in fertilized treatments, with seedlings in RH-C-S the shortest, followed by seedlings in RH-S-TS. RCDs of seedlings were larger in fertilized C-S-TS, RH-S-TS, TS-C-S, and S-C-TS than those in RH-C-S. Seedlings in C-S-TS, TS-C-S, and S-C-TS had the largest RCDs, and were significantly different from those in the RH-S-TS. Among the non-fertilized medium types, seedlings in the rice hull-containing RH-S-TS and RH-C-S treatments had the smallest RCDs (Table 4). Sturdiness was affected by fertilization regardless of medium types. In general, the seedlings in the rice hull-containing media (RH-S-TS and RH-C-S) were less sturdy (Table S3).

Seedling biomass production was enhanced by fertilization in all medium types, which resulted in greater root dry weight, shoot dry weight, and total seedling dry weights than in non-fertilized medium types (Table 4). Among the fertilized media, soil, sand, and compost-containing media (C-S-TS, TS-C-S, and S-C-TS) were among those with the highest root dry weights, shoot dry weights, and total seedling dry weights, whereas rice hull-containing media (RH-S-TS and RH-C-S) were among those with lower dry weights (Table 4). Although lower in root, shoot, and total dry weight, RH-S-TS was not statistically different from C-S-TS and TS-C-S when fertilized. Shoot dry weight of fertilized RH-S-TS also did not differ from those in fertilized S-C-TS. With fertilization, root, shoot, and total dry weight of RH-C-S were significantly lower than C-S-TS, TS-C-S and S-C-TS, but not lower than RH-S-TS. Within the non-fertilized medium types, C-S-TS, TS-C-S, and S-C-TS resulted in higher root, shoot and total dry weights than seedlings in the non-fertilized RH-S-TS and RH-C-S media (Table 4). 
Table 3. Analyses of variance showing $P$-values from testing the effects of Media, Fertilizer and the Media $\times$ Fertilizer interaction $(\alpha=0.05)$ for nursery morphological attributes and simulated drought test growth and survival of E. benthamii seedlings.

\begin{tabular}{cccc}
\hline Response Variable & Media & Fertilizer & Media $\times$ Fertilizer \\
\hline Height $(\mathrm{cm})$ & $<0.0001$ & $<0.0001$ & $<0.0001$ \\
RCD $(\mathrm{mm})$ & $<0.0001$ & $<0.0001$ & $<0.0001$ \\
Root dwt $(\mathrm{g})$ & $<0.0001$ & $<0.0001$ & 0.0080 \\
Shoot dwt (g) & $<0.0001$ & $<0.0001$ & 0.0020 \\
Total dwt (g) & $<0.0001$ & $<0.0001$ & 0.0030 \\
R:S Ratio & $<0.0001$ & $<0.0001$ & $<0.0001$ \\
DQI & $<0.0001$ & $<0.0001$ & $<0.0001$ \\
FOLRs & $<0.0001$ & $<0.0001$ & 0.0030 \\
Height $(\mathrm{cm})-$ RG & $<0.0001$ & $<0.0001$ & $<0.0001$ \\
RCD $(\mathrm{mm})-$ RG & $<0.0001$ & $<0.0001$ & 0.0030 \\
Height $(\mathrm{cm})-$ AG & $<0.0001$ & 0.9400 & $<0.0001$ \\
RCD $(\mathrm{mm})-$ AG & $<0.0001$ & $<0.0001$ & $<0.0001$ \\
SurvDays & $<0.0001$ & 0.0030 & $<0.0001$ \\
\hline
\end{tabular}

RCD: root collar diameters, R:S ratio: root-to-shoot ratio, dwt: dry weight, DQI: Dickson quality index, FOLRs: first order lateral roots, RG: relative growth, AG: absolute growth, SurvDays: number of survival days (number of days until death).

Table 4. Least square means with standard error in parenthesis for Media $\times$ Fertilizer treatment combinations for E. benthamii seedlings nursery morphological attributes. The sample size $(n)$ was 180 for all variables except $n=70$ for FORLs.

\begin{tabular}{ccccccccc}
\hline Treatments & Height $(\mathbf{c m})$ & RCD $(\mathbf{m m})$ & Root dwt $\mathbf{( g})$ & Shoot dwt $\mathbf{( g )}$ & Total dwt $\mathbf{( g )}$ & R:S Ratio & DQI & FOLRs \\
\hline C-S-TS (F) & $51.9(1.69) \mathrm{ab} \ddagger$ & $6.2(0.30) \mathrm{a}$ & $5.93(0.89) \mathrm{ab}$ & $7.22(0.94) \mathrm{a}$ & $13.16(1.82) \mathrm{ab}$ & $0.76(0.04) \mathrm{c}$ & $1.64(0.28) \mathrm{ab}$ & $68(4.0) \mathrm{bc}$ \\
TS-C-S (F) & $55.5(1.41) \mathrm{a}$ & $7.0(0.27) \mathrm{a}$ & $5.59(0.89) \mathrm{ab}$ & $7.24(0.93) \mathrm{a}$ & $12.82(1.80) \mathrm{ab}$ & $0.73(0.04) \mathrm{c}$ & $1.50(0.27) \mathrm{ab}$ & $79(4.4) \mathrm{ab}$ \\
S-C-TS (F) & $57.3(1.85) \mathrm{a}$ & $7.0(0.33) \mathrm{a}$ & $7.28(0.94) \mathrm{a}$ & $8.48(0.89) \mathrm{a}$ & $15.76(1.80) \mathrm{a}$ & $0.81(0.04) \mathrm{c}$ & $2.02(0.31) \mathrm{a}$ & $92(5.4) \mathrm{a}$ \\
RH-S-TS (F) & $49.4(2.46) \mathrm{bc}$ & $5.3(0.26) \mathrm{b}$ & $3.66(0.34) \mathrm{b}$ & $5.18(0.45) \mathrm{ab}$ & $8.84(0.77) \mathrm{ab}$ & $0.71(0.03) \mathrm{c}$ & $0.88(0.10) \mathrm{bc}$ & $69(5.6) \mathrm{abc}$ \\
RH-C-S (F) & $44.7(1.22) \mathrm{c}$ & $4.2(0.12) \mathrm{c}$ & $2.92(0.24) \mathrm{bc}$ & $3.47(0.29) \mathrm{bc}$ & $6.39(0.52) \mathrm{bc}$ & $0.84(0.03) \mathrm{c}$ & $0.59(0.06) \mathrm{dc}$ & $57(3.7) \mathrm{bc}$ \\
C-S-TS (NF) & $38.3(1.42) \mathrm{d}$ & $3.9(0.17) \mathrm{c}$ & $1.70(0.20) \mathrm{cd}$ & $2.17(0.24) \mathrm{cd}$ & $3.87(0.43) \mathrm{dc}$ & $0.75(0.02) \mathrm{c}$ & $0.34(0.05) \mathrm{de}$ & $48(3.4) \mathrm{c}$ \\
TS-C-S (NF) & $35.5(1.50) \mathrm{d}$ & $3.6(0.12) \mathrm{c}$ & $1.37(0.13) \mathrm{d}$ & $1.85(0.15) \mathrm{d}$ & $3.22(0.28) \mathrm{d}$ & $0.68(0.03) \mathrm{c}$ & $0.28(0.03) \mathrm{e}$ & $48(2.1) \mathrm{c}$ \\
S-C-TS (NF) & $35.9(2.10) \mathrm{d}$ & $3.7(0.16) \mathrm{c}$ & $1.63(0.19) \mathrm{d}$ & $1.94(0.23) \mathrm{d}$ & $3.56(0.42) \mathrm{d}$ & $0.82(0.03) \mathrm{c}$ & $0.32(0.05) \mathrm{e}$ & $55(2.2) \mathrm{c}$ \\
RH-S-TS (NF) & $9.6(0.94) \mathrm{e}$ & $0.9(0.13) \mathrm{d}$ & $0.08(0.01) \mathrm{e}$ & $0.06(0.01) \mathrm{e}$ & $0.14(0.02) \mathrm{e}$ & $1.46(0.09) \mathrm{a}$ & $0.01(0.00) \mathrm{f}$ & $15(1.1) \mathrm{d}$ \\
RH-C-S (NF) & $13.7(1.25) \mathrm{e}$ & $1.1(0.09) \mathrm{d}$ & $0.12(0.02) \mathrm{e}$ & $0.12(0.02) \mathrm{f}$ & $0.24(0.05) \mathrm{e}$ & $1.08(0.04) \mathrm{b}$ & $0.02(0.00) \mathrm{f}$ & $18(2.5) \mathrm{d}$ \\
\hline
\end{tabular}

$\ddagger$ Lowercase letters within a column with the same letter are not significantly different using Tukey-Kramer multiple comparison test at $\alpha=0.05$. 
DQI within the fertilized treatments was higher in soil, sand and compost containing media (C-S-TS, TS-C-S, and S-C-TS); however, DQI of TS-C-S was not different from RH-S-TS. The media containing rice hulls (RH-S-TS and RH-C-S) produced seedlings with lower DQIs with and without fertilization (Table 4).

Fertilization resulted in seedlings with lower R:S ratios in the two media containing rice hulls (RH-S-TS and RH-C-S) compared to seedlings in these media without fertilization, but not in media containing soil, sand and compost (C-S-TS, TS-C-S and S-C-TS). Among the fertilized treatments, the $\mathrm{R}: S$ ratios of all the media were not significantly different from each other. Among non-fertilized medium types, R:S ratio of rice hulls containing RH-S-TS and RH-C-S was significantly higher than C-S-TS, TS-C-S, and S-C-TS (Table 4).

The number of FOLRs among fertilized medium types C-S-TS, TS-C-S, and S-C-TS were greater than the other two media. FOLRs of the fertilized soil, sand, and rice hull medium (RH-S-TS) was significantly less than S-C-TS. Also FOLRs of fertilized sand, compost, and rice hulls medium (RH-C-S) was significantly less than TS-C-S and S-C-TS. Under the no fertilizer regime, C-S-TS, TS-C-S and S-C-TS produced the highest mean FOLRs. Non-fertilized RH-S-TS and RH-C-S had the fewest FOLRs (Table 4). Nearly all of the spiraled roots occurred in the bottom portion of the polybags. Larger fertilized seedlings had higher mean number of spiraled roots than non-fertilized small seedlings (Table S3).

\subsection{Drought Test Growth and Survival}

The main effects of media, fertilizer, and media $\times$ fertilizer interaction was highly significant for the drought test growth and survival variables, except for the non-significant main effect of fertilizer for height absolute growth (Table 3). The seedlings grew for 30 days before the induced drought period in the simulated outplanting experiment. Seedlings from the fertilized media remained among the largest in height and RCD (Figure 1). Relative height and diameter growth was greatest in seedlings from the two non-fertilized, rice hull-containing media.

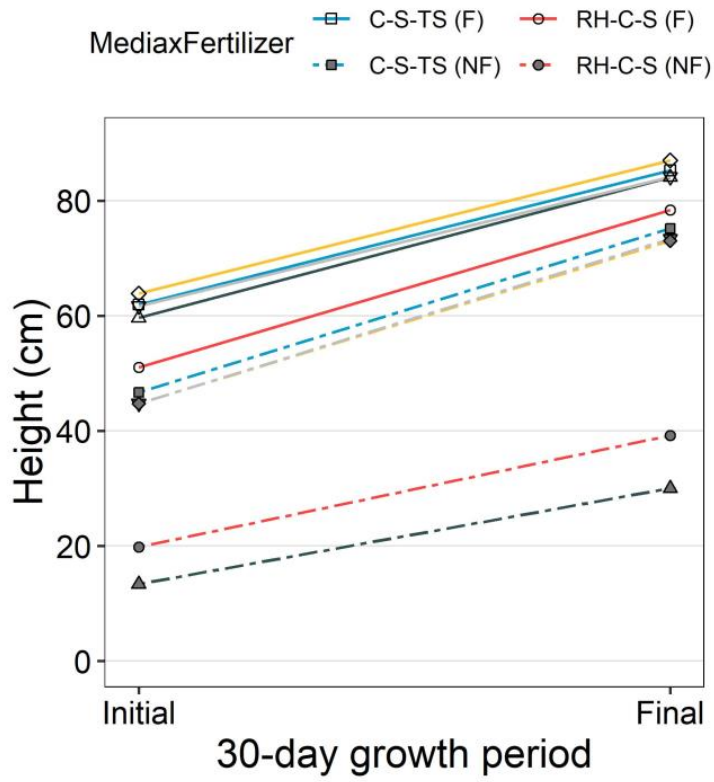

(a)

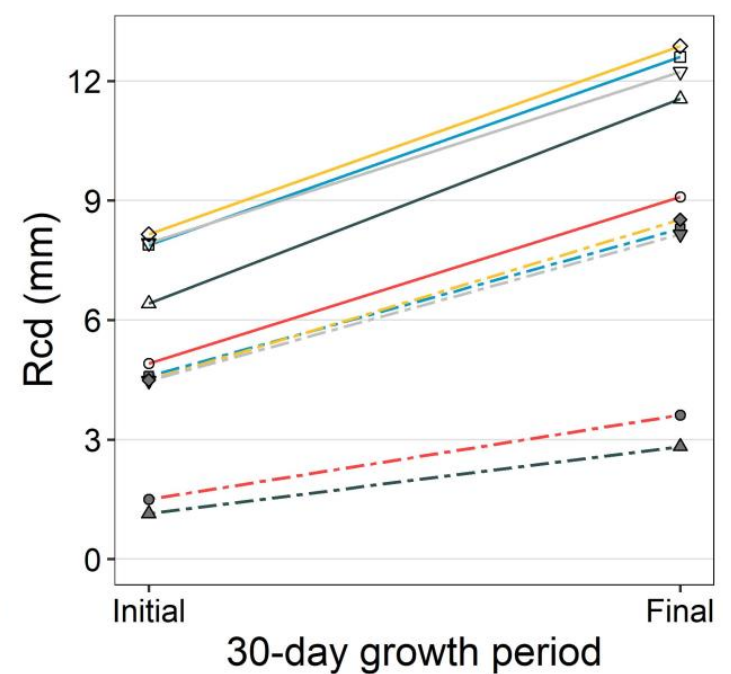

(b)

Figure 1. Simulated outplanting-30-day height (a) and RCD (b) growth of seedlings in media $\times$ fertilizer treatment combinations before induced drought test.

There were significant medium $\times$ fertilizer treatment interaction effects on SurvDays, with treatment means ranging from 33 to 51 days (Table 5). Seedlings from the non-fertilized RH-S-TS and RH-C-S treatments survived the longest under drought stress, although those in non-fertilized 
RH-C-S were not significantly different than those in fertilized C-S-TS and TS-C-S. Seedlings in the S-C-TS medium type performed relatively poorly under drought stress, both with and without nursery fertilization (Table 5). Seedlings under these treatments had the highest growth and biomass accumulation during the nursery phase. Seedling height, RCD, and total dry weight were negatively correlated with SurvDays, while R:S ratio was positively correlated with simulated drought SurvDays (Figure 2).

Table 5. Least square means with standard error in parenthesis for Media $\times$ Fertilizer treatment combinations for simulated outplanting drought test growth and survival. The sample size was 120 .

\begin{tabular}{cccccc}
\hline Treatments & Height-RG (\%) & RCD-RG (\%) & Height-AG (cm) & RCD-AG (mm) & SurvDays \\
\hline C-S-TS (F) & $38.1(1.53) \mathrm{d} \ddagger$ & $65.8(5.11) \mathrm{b}$ & $23.3(0.78) \mathrm{bcde}$ & $4.8(0.23) \mathrm{ab}$ & $39.8(2.12) \mathrm{bc}$ \\
TS-C-S (F) & $37.8(2.49) \mathrm{d}$ & $61.5(6.20) \mathrm{b}$ & $22.4(1.02) \mathrm{de}$ & $4.3(0.21) \mathrm{abcd}$ & $42.2(2.35) \mathrm{bc}$ \\
S-C-TS (F) & $37.6(2.15) \mathrm{d}$ & $62.8(4.37) \mathrm{b}$ & $23.1(0.90) \mathrm{cde}$ & $4.7(0.22) \mathrm{abc}$ & $33.1(2.01) \mathrm{c}$ \\
RH-S-TS (F) & $42.2(2.07) \mathrm{d}$ & $89.7(9.69) \mathrm{b}$ & $24.4(0.88) \mathrm{abcde}$ & $5.1(0.25) \mathrm{a}$ & $37.1(2.20) \mathrm{c}$ \\
RH-C-S (F) & $56.7(4.67) \mathrm{cd}$ & $87.9(4.96) \mathrm{b}$ & $27.3(1.60) \mathrm{abcd}$ & $4.2(0.21) \mathrm{abcd}$ & $38.1(2.22) \mathrm{c}$ \\
C-S-TS (NF) & $64.2(3.77) \mathrm{c}$ & $87.1(5.92) \mathrm{b}$ & $28.4(1.15) \mathrm{ab}$ & $3.7(0.19) \mathrm{cd}$ & $35.9(2.30) \mathrm{c}$ \\
TS-C-S (NF) & $67.0(3.19) \mathrm{c}$ & $84.5(4.70) \mathrm{b}$ & $28.6(0.99) \mathrm{a}$ & $3.7(0.18) \mathrm{d}$ & $35.2(2.39) \mathrm{c}$ \\
S-C-TS (NF) & $67.5(4.31) \mathrm{c}$ & $93.9(5.55) \mathrm{b}$ & $28.3(0.99) \mathrm{abc}$ & $4.0(0.18) \mathrm{bcd}$ & $33.9(2.07) \mathrm{c}$ \\
RH-S-TS (NF) & $132.0(9.98) \mathrm{a}$ & $166.3(16.16) \mathrm{a}$ & $16.7(1.40) \mathrm{f}$ & $1.7(0.16) \mathrm{e}$ & $51.4(1.90) \mathrm{a}$ \\
RH-C-S (NF) & $106.0(8.04) \mathrm{b}$ & $155.1(15.11) \mathrm{a}$ & $19.4(1.41) \mathrm{ef}$ & $2.1(0.18) \mathrm{e}$ & $48.9(1.93) \mathrm{ab}$ \\
\hline
\end{tabular}

$\ddagger$ Lowercase letters within a column with the same letter are not significantly different using Tukey-Kramer multiple comparison test at $\alpha=0.05$.
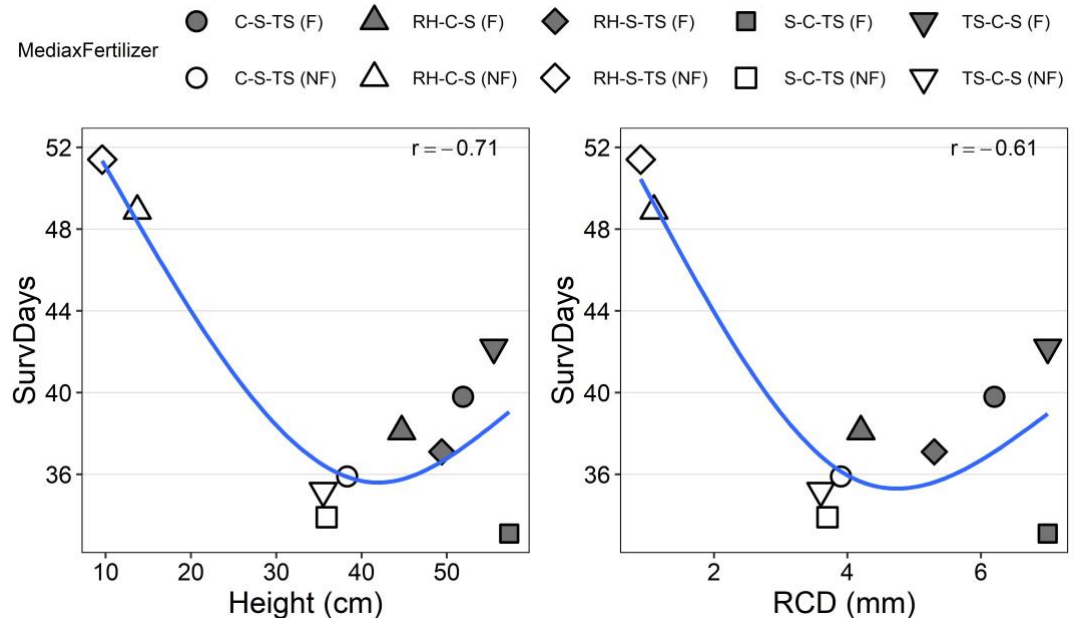

(a)

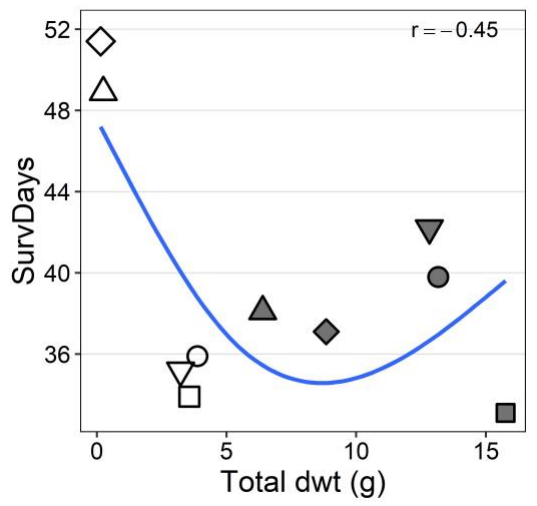

(c)

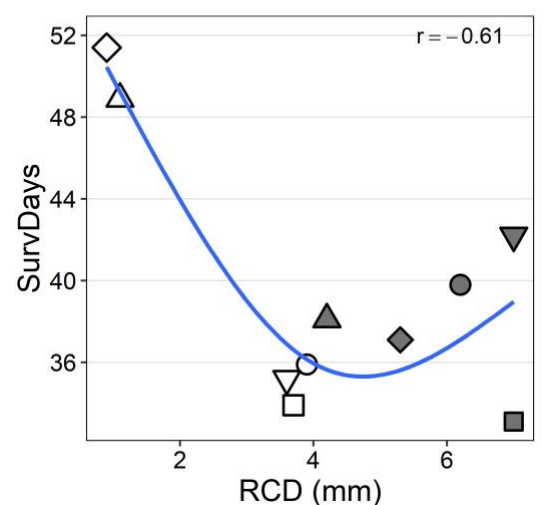

(b)

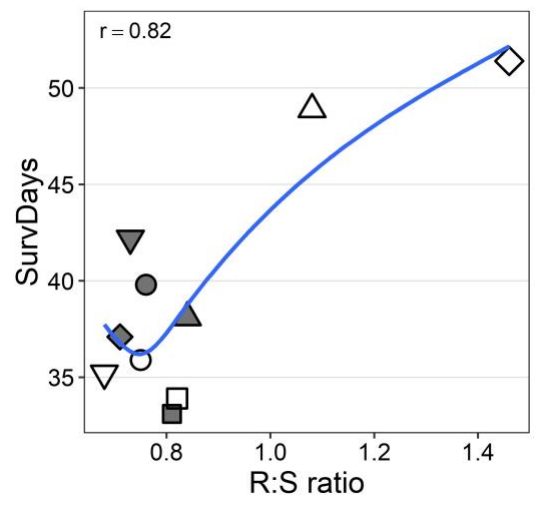

(d)

Figure 2. Relationship and correlation between simulated drought mean number of survival days (SurvDays) and nursery morphological variables mean height (a), RCD (b), total dry weight (c), and $\mathrm{R}: \mathrm{S}$ ratio $(\mathbf{d})$. 
Survival of E. benthamii seedlings also varied among treatments over time (Figure 3). There was no change in survival in the first week of drought stress. However, during weeks two and three, there was a noticeable decline in survival of seedlings in all treatments except non-fertilized RH-S-TS and RH-C-S. Non-fertilized RH-S-TS and RH-C-S treatments maintained their survival rate at 95 to 100\% through week five, whereas survival of other treatments at that point was lower than $80 \%$. In weeks 5 to 7, fertilized TS-C-S and C-S-TS treatments showed some resistance to drought stress and kept their survival 60 to $70 \%$. Seedlings in S-C-TS media were all dead at the end of week eight. By the end of week 10, survival in all treatments was $0 \%$ except non-fertilized RH-S-TS and RH-C-S, in which survival was 10-15\% (Figure 3).

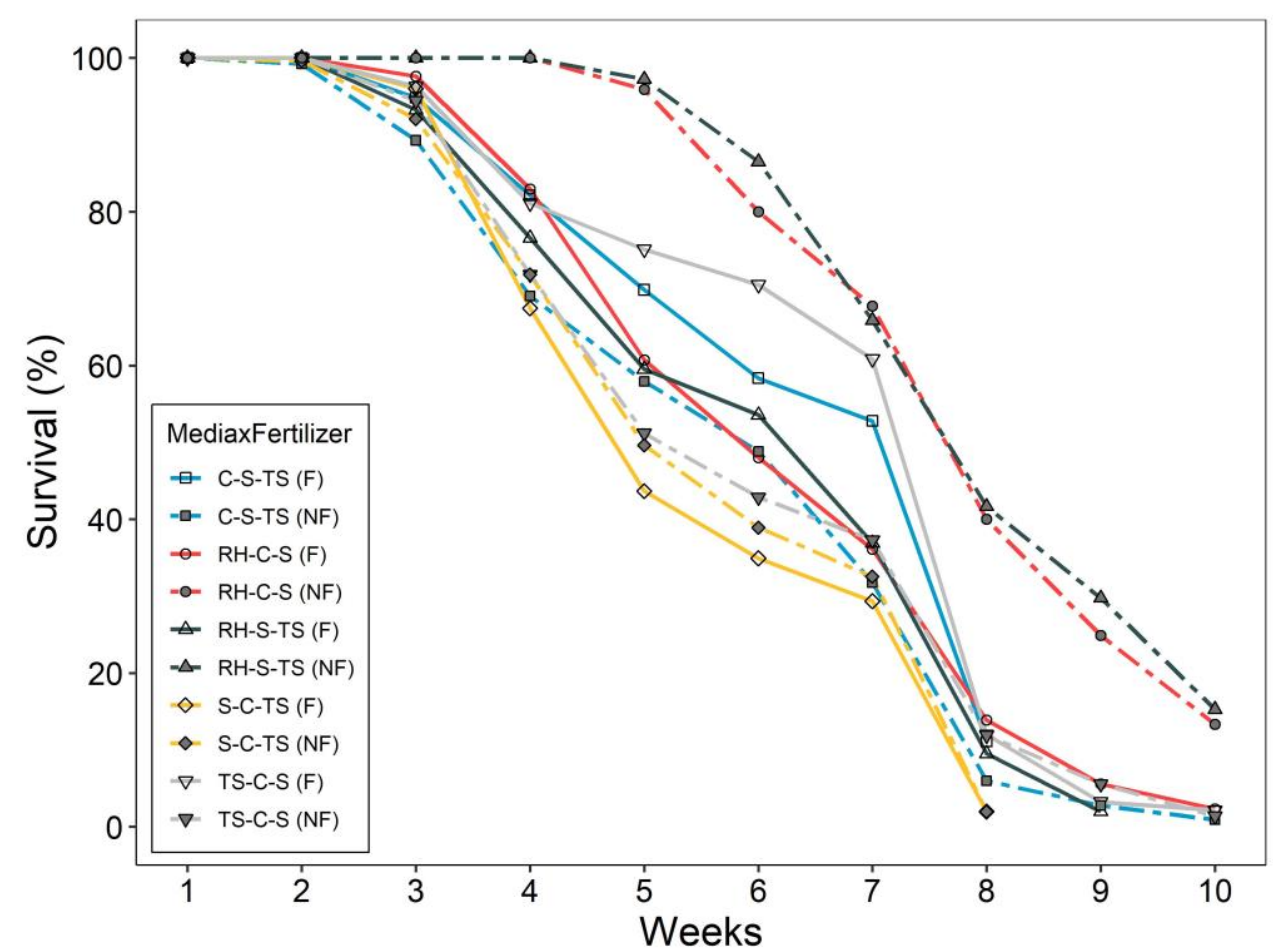

Figure 3. Simulated outplanting-line plot of seedlings survival from the beginning of drought stress period until complete death. Each line represents one Media $\times$ Fertilizer treatment combination. Solid lines represent non-fertilized treatments and dashed lines represent fertilized treatments. Smaller seedlings from non-fertilized rice hull treatments showed higher tolerance to induced drought over time.

The xylem water potential decreased in all treatments as the number of days under drought stress increased, with the exception of the non-fertilized RH-S-TS and RH-C-S treatments. Xylem water potential of non-fertilized RH-S-TS and RH-C-S treatments did not change at any of the three measurement times. In other treatments, however, water potential decreased dramatically after day 16. Xylem water potential was lowest in fertilized C-S-TS and non-fertilized TS-C-S treatments in day 25 (Figure 4). The relationship between pre-dawn xylem water potential and SurvDays was positive, but only significant in Day 16 of the drought stress period (Figure 5). 


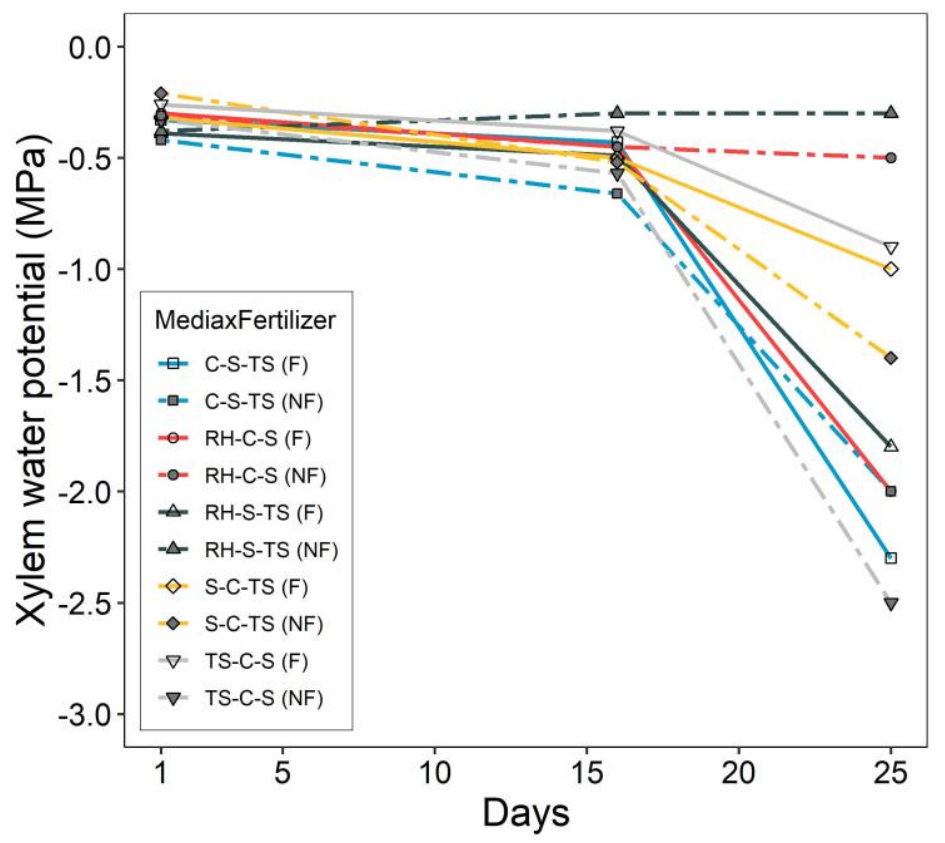

Figure 4. Simulated outplanting-pre-dawn xylem water potential $(\mathrm{MPa})$ of Media $\times$ Fertilizer treatments measured in day 1 , day 16, and day 25 of drought stress period. Smaller seedlings maintained xylem water potential until week five under induced drought.

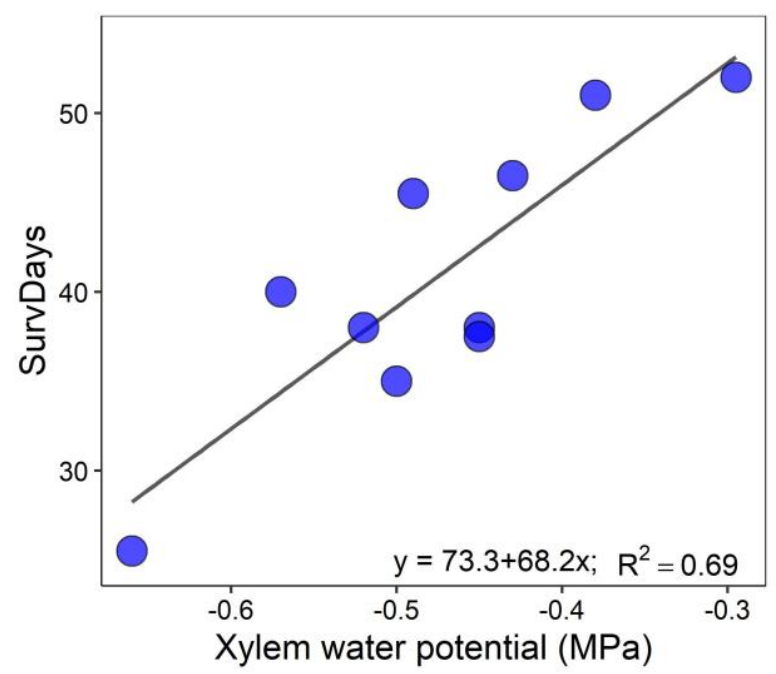

Figure 5. Simulated outplanting-scatterplot of response variable SurvDays versus pre-dawn xylem water potential measured at day 16 of drought stress period $(p$-value $=0.002)$. Individual circles represent treatment means. Larger seedlings with lower xylem water potential survived fewer days than treatments with higher water potential.

\section{Discussion}

One of the principal objectives of this study was to test the effects of substituting rice hulls for either compost or top soil. Without fertilization, seedlings in media containing the rice hulls were substantially smaller compared to those grown in the corresponding media (C-S-TS and TS-C-S). Part of this effect can be attributed to insufficient nutrition, as rice hulls provided substantially less $\mathrm{N}$ than the other medium components (Table S1). The requirement for additional nutrition was also demonstrated by the greater overall growth of seedlings in these media when fertilization was applied. Additionally, the high C:N ratio (85:1) associated with the use of rice hulls [49] may have contributed to $\mathrm{N}$ depletion, even when fertilizer was applied. Although all seedlings received the same quantity of water at each irrigation period, there were observed growth differences among treatments. This 
may be related, in part, to the differences in water availability and holding capacity associated with the range of media types. The lower bulk density and greater porosity of the media containing rice hulls suggests that, during the periods between irrigations, the seedlings in these media had less water available to them. Rice hulls have been previously used as a successful alternative growing media in place of vermiculite and other materials [22]. Although our study tested parboiled (but not composted) rice hulls, incorporation of this medium component might yield better growth results if the rice hulls are in composted form. Einert and Guidry [26] found increased growth of Juniperus chinensis L. seedlings growing in media containing 50\% composted rice hulls plus 50\% soil and 40\% composted rice hulls plus $60 \%$ compost, compared to media containing parboiled rice hulls. In addition, the substantial growth suppression found with the use of $50 \%$ parboiled rice hulls without fertilization does not preclude that smaller proportions of rice hulls could allow for improvement of medium physical properties without sacrificing acceptable growth in the nursery. Dueitt [49] reported that both composted and fresh rice hulls can be used as a substitute for vermiculite, but with increasing proportions in the mixture, it could result in a decreased plant growth due to its lower nutritional value, as was found in our study. Further research is required to examine the proportions of rice hulls and levels of supplied nutrients that will allow for optimal seedling growth.

With the imposition of drought after the simulated outplanting, seedlings grown in non-fertilized, rice hull-containing media survived longer and had greater relative height and diameter growth rates compared to other non-fertilized mediums. This is likely due to the small shoots and large R:S ratios of these seedlings after the nursery phase, which may have persisted through the 30-day outplanting phase. This is supported by the finding that seedlings from these treatments maintained their XWP throughout the drought period of 25 days. Small shoot sizes in non-fertilized rice hull-containing media resulted in lower transpiring surface area. It is not possible from our results to conclude whether small shoot size or R:S ratio was most important for maintenance of XWP and enhanced survival of the seedlings in the non-fertilized, rice hull-containing media, as both occurred in these seedlings, compared with the seedlings from all other treatments. In addition, RCD and total dry weight were also negatively correlated with survival. The large morphological differences in all these variables between seedlings grown in the two non-fertilized media types as opposed to all the other media and fertilization treatment combinations strongly affected the fit in the scatterplots (Figure 2).

Although the range of seedling sizes produced in this experiment is most likely larger than is used for operational planting programs, other studies have shown a relationship between both seedling size and R:S ratio and survival on droughty sites. Seedlings with larger shoot sizes can have better height growth and survival on mesic sites [34]; however, they can have decreased survival on drier sites [50,51]. Larger shoot size increases vulnerability of newly planted seedlings to mortality due to increased transpiration and water loss [52]. Ivetic et al. [53] observed a negative relationship between survival and shoot height, height/diameter ratio and shoot to root ratio in Austrian pine seedlings. Tuttle et al. [50] observed that height of loblolly pine seedlings was positively correlated with survival on good sites; however, it was negatively correlated on adverse sites. This indicates that, under drought stress, seedlings with larger shoot systems transpire water more quickly, because of greater leaf area [3]. In this study, the results from simulated outplanting test may not necessarily reflect the performance of the seedlings if they were planted into an actual outplanting. However, the results indicate that size of the newly planted seedlings may affect early post-planting survival in arid outplanting conditions where seedlings are planted into soil with adequate soil moisture, but then experience prolonged drought.

A second objective of the experiment was to test the effects of fertilization across all medium combinations. Although fertilization increased growth of the seedlings in all media, the R:S ratios did not differ, except for those in the rice hull-containing media. Furthermore, fertilization during the nursery stage did not have consistent effects on the maintenance of XWP through 25 days nor on survival during droughty conditions. Potentially, growers could optimize fertilization levels to produce seedlings for particular sites and environments, without fundamentally altering the R:S ratios 
of the seedlings produced. As good survival is a key goal of afforestation and reforestation programs in arid environments, selection of growing media type and fertilizer levels are techniques that can affect seedling attributes that ultimately affect survival. While very small seedlings might be more resistant to water stress, they could be more sensitive to competition from weeds that could result in lower survival. Thus, growers and foresters should assess their sites and utilize the target seedling concept [1] by manipulating medium components and fertilization to plant seedlings with the highest probability of good survival and growth.

However, a note of caution should be added when considering fertilization for seedlings grown in polybags. Because, in our study, fertilization also increased the number of spiraled roots in all media (Table S3), it is necessary to balance growth with container size, in this case polybags. The use of polybags, even those containing air holes, such as the ones we used, can result in excessive amounts of spiraled roots [54], compared to containers that are designed to prevent them. However, in some developing countries, polybags are a commonly used option, thus, growers should be aware that too much root growth could lead to spiraling and, potentially, additional transplant shock, after removal from the bags. Managing the fertilization levels, as well as the time that seedlings are kept in the bags, can be optimized to produce seedlings that will perform well after transplant. Future studies could examine differing levels of fertilization to achieve this optimization.

\section{Conclusions}

The purpose of this study was to assess morphological responses of seedlings grown under different media and fertilization environments in the nursery followed by a simulated outplanting to test drought tolerance. Results showed that using fertilizer in the nursery, regardless of media, typically promoted greater growth responses. In contrast, the inclusion of parboiled rice hulls as part of the media mixture reduced growth of seedlings compared to compost, sand, and topsoil mixtures. However, these smaller seedlings exhibited substantial relative growth during the 30-day well-watered simulated outplanting and greater drought resistance after the imposition of drought. Seedlings with small shoots and high R:S ratios are expected to have higher survival after planting due to lower transpiration rates as a result of smaller leaf areas.

Inferences drawn from this study should be limited to the simulated outplanting environment. Planting into actual field environments will likely subject seedlings to a myriad of biotic (i.e., herbivory and competing vegetation) and abiotic (i.e., temperature and precipitation) stresses that did not exist in this experiment. A critical next step is to examine field performance of outplanted seedlings that use medium components and fertilization in the nursery to manipulate size and R:S ratios in seedlings targeted for planting on challenging reforestation and restoration sites. These practical nursery manipulations are especially important to outplanting efforts in many developing and resource-limited countries.

Supplementary Materials: The following are available online at http://www.mdpi.com/1999-4907/10/7/543/s1, Table S1: Chemical analysis of media mixture and substrates, Table S2: Foliar nutrient contents and concentrations for Media $\times$ Fertilizer treatments, Table S3: Least square means for sturdiness number of spiraled roots and number of active root tips.

Author Contributions: M.N.S. and B.G. conceived the experiment and developed the experimental design. M.N.S. developed and carried out the specific methodology. M.N.S., O.T.B., and T.H.S. contributed to data analysis. B.G. secured funding for the research and was responsible for overall project administration. B.G., O.T.B., and T.H.S. supervised the research of M.N.S. as part of his M.N.S. program. All authors contributed to the preparation of the manuscript.

Funding: This article is made possible by the support of the United States Agency for International Development (USAID) [AID-306-A-00-11-00516]. The contents are the responsibility of North Carolina State University and do not necessarily reflect the views of USAID or the United States Government.

Acknowledgments: We appreciate assistance of the NCSU Cooperative Tree Improvement Program faculty and staff, Steve McKeand, Jadie Andrews, Josh Steiger, and Austin Heine, for their help and use of space and equipment. We thank Jose Stape and Kevin Hall for use of the Forest Productivity Cooperative laboratory and resources. Thanks to John Frampton for his assistance in statistical analysis of this research data. 
Conflicts of Interest: The authors declare no conflict of interest.

\section{References}

1. Landis, T.D. The target plant concept. Nurs. Man. Native Plants Guide Tribal Nurseries 2009, 1, $15-31$.

2. Harper, R.J.; Smettem, K.R.J.; Carter, J.O.; McGrath, J.F. Drought deaths in Eucalyptus globulus (Labill.) plantations in relation to soils, geomorphology and climate. Plant Soil 2009, 324, 199. [CrossRef]

3. Burdett, A.N. Physiological processes in plantation establishment and the development of specifications for forest planting stock. Can. J. For. Res. 1990, 20, 415-427. [CrossRef]

4. Slot, M.; Poorter, L. Diversity of tropical tree seedling responses to drought. Biotropica 2007, 39, 683-690. [CrossRef]

5. Davis, A.S.; Jacobs, D.F. Quantifying root system quality of nursery seedlings and relationship to outplanting performance. New For. 2005, 30, 295-311. [CrossRef]

6. Jacobs, D.F.; Salifu, K.F.; Seifert, J.R. Relative contribution of initial root and shoot morphology in predicting field performance of hardwood seedlings. New For. 2005, 30, 235-251. [CrossRef]

7. Tsakaldimi, M.; Ganatsas, P.; Jacobs, D.F. Prediction of planted seedling survival of five Mediterranean species based on initial seedling morphology. New For. 2013, 44, 327-339. [CrossRef]

8. Thompson, B.E. Seedling Morphological Evaluation: What You Can Tell by Looking; Oregon State University: Corvallis, OR, USA, 1985.

9. Sharma, R.K.; Mason, E.G.; Sorensson, C. Impact of planting stock quality on initial growth and survival of radiata pine clones and modelling initial growth and survival. N. Z. J. For. 2007, 52, 14.

10. Pawsey, C.K. Survival and early development of Pinus radiata as influenced by size of planting stock. Aust. For. Res. 1972, 5, 13-24.

11. Mullin, R.E.; Svaton, J. A grading study with white spruce nursery stock. Commonw. For. Rev. 1972, 51, 62-69.

12. Lamhamed, M.S.; Bernier, P.Y.; Hébert, C. Effect of shoot size on the gas exchange and growth of containerized Picea mariana seedlings under different watering regimes. New For. 1997, 13, 209-223. [CrossRef]

13. Haase, D.L. Understanding forest seedling quality: Measurements and interpretation. Tree Plant. Notes 2008, 52, 24-30.

14. Sands, R. Transplanting stress in radiata pine. Aust. For. Res. 1984, 14, 67-72.

15. Grossnickle, S.C. Why seedlings survive: Influence of plant attributes. New For. 2012, 43, 711-738. [CrossRef]

16. Harrington, J.T.; Mexal, J.G.; Wagner, A.M.; Parsons, T. The state and challenges of conservation nurseries in Afghanistan. In National Proceedings: Forest and Conservation Nursery Associations-2011. Proc. RMRS-P-68; Haase, D.L., Pinto, J.R., Riley, L.E., Eds.; USDA Forest Service, Rocky Mountain Research Station: Fort Collins, CO, USA, 2012; pp. 59-64.

17. Wilkinson, K.M.; Landis, T.D.; Haase, D.L.; Daley, B.F.; Dumroese, R.K. Tropical Nursery Manual: A Guide to Starting and Operating a Nursery for Native and Traditional Plants. In Agriculture Handbook 732; U.S. Department of Agriculture, Forest Service: Washington, DC, USA, 2014; 376p.

18. Shrivastava, R.; Nanhorya, R.; Upadhyaya, J.K. Selection of proper potting mixture for root trainer of eucalyptus hybrid. Indian For. 1998, 124, 502-510.

19. Dumroese, R.K.; Landis, T.D.; Luna, T.; Hernández, G. Simple Methods for Raising Tree and Shrub Seedlings in Afghanistan; Agency for International Development and U.S. Department of Agriculture, Foreign Agriculture Service, Office of Capacity Building and Development: Washington, DC, USA, 2008; 63p.

20. Evans, M.R.; Gachukia, M. Fresh parboiled rice hulls serve as an alternative to perlite in greenhouse crop substrates. HortScience 2004, 39, 232-235. [CrossRef]

21. Whitcomb, C.E. Plant Production in Containers; Lacebark Publications: Stillwater, MN, USA, 1984.

22. Miller, J.H.; Jones, N. Organic and Compost-Based Growing Media for Tree Seedling Nurseries; World Bank Publications: Washington, DC, USA, 1995; Volume 264.

23. Tsakaldimi, M. Kenaf (Hibiscus cannabinus L.) core and rice hulls as components of container media for growing Pinus halepensis M. seedlings. Bioresour. Technol. 2006, 97, 1631-1639. [CrossRef]

24. Antônio, A.D.C.; Alves, J.D.F.; de Faria, B.R.; Almeida, J. Use of brewing biosolids as substrate for production of Eucalyptus seedlings: Analysis of early seedling growth and environmental aspects. Engenharia na Agricultura 2010, 18, 305-309. [CrossRef] 
25. Kratz, D.; Wendling, I. Seedlings of Eucalyptus dunnii grown in renewable substrate. Floresta 2013, 43, 125-135. [CrossRef]

26. Einert, A.E.; Guidry, G. Rice hulls and hull compost in growing media for container-grown junipers. Ark. Farm Res. 1975, 24, 2.

27. Van den Driessche, R. Nursery growth of conifer seedlings using fertilizers of different solubilities and application time, and their forest growth. Can. J. For. Res. 1988, 18, 172-180. [CrossRef]

28. Duryea, M.L.; Landis, T.D. Forest Nursery Manual: Production of Bareroot Seedlings; Springer Science \& Business Media: Berlin, Germany, 2012; Volume 11.

29. Oliet, J.A.; Planelles, R.; Artero, F.; Valverde, R.; Jacobs, D.F.; Segura, M.L. Field performance of Pinus halepensis planted in Mediterranean arid conditions: Relative influence of seedling morphology and mineral nutrition. New For. 2009, 37, 313-331. [CrossRef]

30. Chamshama, S.A.O.; Hall, J.B. Effects of nursery treatments on Eucalyptus camaldulensis field establishment and early growth at Mafiga, Morogoro, Tanzania. For. Ecol. Manag. 1987, 21, 91-108. [CrossRef]

31. Stahl, J.; Ernani, P.R.; Gatiboni, L.C.; Chaves, D.M.; Neves, C.U. Dry matter yield and nutritional efficiency of Eucalyptus benthamii and Eucalyptus dunnii clones due to addition of phosphorus rates to the soil. Cienc. Florest. 2013, 23, 287-295.

32. Luis, V.C.; Puértolas, J.; Climent, J.; Peters, J.; González-Rodríguez, Á.M.; Morales, D.; Jiménez, M.S. Nursery fertilization enhances survival and physiological status in Canary Island pine (Pinus canariensis) seedlings planted in a semiarid environment. Eur. J. For. Res. 2009, 128, 221-229. [CrossRef]

33. Villar-Salvador, P.; Peñuelas, J.L.; Nicolás-Peragón, J.L.; Benito, L.F.; Domínguez-Lerena, S. Is nitrogen fertilization in the nursery a suitable tool for enhancing the performance of Mediterranean oak plantations? New For. 2013, 44, 733-751. [CrossRef]

34. Villar-Salvador, P.; Planelles, R.; Enrıquez, E.; Rubira, J.P. Nursery cultivation regimes, plant functional attributes, and field performance relationships in the Mediterranean oak Quercus ilex L. For. Ecol. Manag. 2004, 196, 257-266. [CrossRef]

35. Trubat, R.; Cortina, J.; Vilagrosa, A. Nursery fertilization affects seedling traits but not field performance in Quercus suber L. J. Arid Environ. 2010, 74, 491-497. [CrossRef]

36. Pharis, R.P.; Kramer, P.J. The effects of nitrogen and drought on loblolly pine seedlings. For. Sci. 1964, 10, 143-150.

37. Cromer, R.N.; Cameron, D.M.; Rance, S.J.; Ryan, P.A.; Brown, M. Response to nutrients in Eucalyptus grandis. 1. Biomass accumulation. For. Ecol. Manag. 1993, 62, 211-230. [CrossRef]

38. Butnor, J.R.; Johnsen, K.H.; Anderson, P.H.; Hall, K.B.; Halman, J.M.; Hawley, G.J.; Maier, C.A.; Schaberg, P.G. Growth, photosynthesis, and cold tolerance of Eucalyptus benthamii planted in the piedmont of North Carolina. For. Sci. 2018, 65, 59-67. [CrossRef]

39. Stanturf, J.A.; Vance, E.D.; Fox, T.R.; Kirst, M. Eucalyptus beyond its native range: Environmental issues in exotic bioenergy plantations. Int. J. For. Res. 2013, 2013. [CrossRef]

40. Davidson, J. Ecological aspects of Eucalyptus plantations. In Proceedings of the Regional Expert Consultation on Eucalyptus, RAPA/FAO, Bangkok, Thailand, 4-8 October 1993; Volume 1, pp. 35-60.

41. Madgwick, H.A.I.; Oliver, G.R.; Frederick, D.J.; Tew, D.T. Estimating the dry weights of Eucalyptus trees-Central North Island, New Zealand. Bioresour. Technol. 1991, 37, 111-114. [CrossRef]

42. Rook, D.A. Seedling development and physiology in relation to mineral nutrition. Conifer Seedl. Miner. Nutr. 1990, 85, 86-105.

43. Allen, C.D.; Breshears, D.D.; McDowell, N.G. On underestimation of global vulnerability to tree mortality and forest die-off from hotter drought in the Anthropocene. Ecosphere 2015, 6, 1-55. [CrossRef]

44. Qaisar, K.N.; Khan, P.A.; Khan, M.A. Container type and growing media for raising quality seedling stock of Cedrus deodara. Indian J. For. India 2008, 31, 383-388.

45. Dickson, A.; Leaf, A.L.; Hosner, J.F. Quality appraisal of white spruce and white pine seedling stock in nurseries. For. Chron. 1960, 36, 10-13. [CrossRef]

46. Isaac, R.A.; Johnson, W.C. Elemental analysis of plant tissue by plasma emission spectroscopy: Collaborative study. J. Assoc. Anal. Chem. US 1985, 68, v499-v505.

47. Mehlich, A. Mehlich 3 soil test extractant: A modification of Mehlich 2 extractant. Commun. Soil Sci. Plant Anal. 1984, 15, 1409-1416. [CrossRef] 
48. Cleary, B.D.; Zaerr, J.B. Pressure chamber techniques for monitoring and evaluating seedling water status. $N$. Z. J. For. Sci. 1980, 10, 133-141.

49. Dueitt, S.D. Rice Hulls as a Substitute for Sphagnum Peat Moss in a Sphagnum Peat-Based Greenhouse Media. Master's Thesis, Mississippi State University, Starkville, MS, USA, 1995.

50. Tuttle, C.L.; South, D.B.; Golden, M.S.; Meldahl, R.S. Relationship between initial seedling height and survival and growth of loblolly pine seedlings planted during a droughty year. South. J. Appl. For. 1987, 11, 139-143.

51. McTague, J.P.; Tinus, R.W. The effects of seedling quality and forest site weather on field survival of ponderosa pine. Tree Plant. Notes 1996, 47, 16-23.

52. Grossnickle, S.C. Importance of root growth in overcoming planting stress. New For. 2005, 30, $273-294$. [CrossRef]

53. Ivetić, V.; Grossnickle, S.; Škorić, M. Forecasting the field performance of Austrian pine seedlings using morphological attributes. IForest-Biogeosci. For. 2016, 10, e1-e9. [CrossRef]

54. Khurram, S.; Burney, O.T.; Morrissey, R.C.; Jacobs, D.F. Bottles to trees: Plastic beverage bottles as an alternative nursery growing container for reforestation in developing countries. PLoS ONE 2017, 12, e0177904. [CrossRef] [PubMed]

(C) 2019 by the authors. Licensee MDPI, Basel, Switzerland. This article is an open access article distributed under the terms and conditions of the Creative Commons Attribution (CC BY) license (http://creativecommons.org/licenses/by/4.0/). 